\title{
Assessment of intradialysis calcium mass balance by a single pool variable-volume calcium kinetic model
}

\author{
Salvatore DI FILIPPO, ${ }^{1}$ Fabio CARFAGNA (D), ${ }^{1}$ Vincenzo LA MILIA, ${ }^{1}$ Antonio BELLASI, ${ }^{2}$ \\ Giustina CASAGRANDE, ${ }^{3}$ Camilla BIANCHI, ${ }^{3}$ Domenico VITO, ${ }^{3}$ \\ Maria Laura COSTANTINO, ${ }^{3}$ Giuseppe ROMBOLÀ, ${ }^{4}$ Claudio MINORETTI, ${ }^{2}$ \\ Carlo SCHÖNHOLZER, ${ }^{5}$ Giuseppe PONTORIERO, ${ }^{1}$ Francesco LOCATELLI ${ }^{1}$ \\ 'Depatments of Nephrology and Dialysis, A. Manzoni Hospital, Lecco, Italy; ${ }^{2}$ Depatments of Nephrology \\ and Dialysis, Sant'Anna Hospital, Como, Italy; ${ }^{3}$ Depatments of Chemistry, Material and Chemical \\ Engineering, Politecnico di Milano, Milano, Italy; ${ }^{4}$ Depatments of Nephrology and Dialysis, Hospital and \\ Macchi Foundation, Varese, Italy; ${ }^{5}$ Depatments of Nephrology and Dialysis, Regional Hospital of
} Lugano, Lugano, Switzerland

\begin{abstract}
Introduction: A reliable method of intradialysis calcium mass balance quantification is far from been established. We herein investigated the use of a single-pool variable-volume Calcium kinetic model to assess calcium mass balance in chronic and stable dialysis patients.

Methods: Thirty-four patients on thrice-weekly HD were studied during 240 dialysis sessions. All patients were dialyzed with a nominal total calcium concentration of $1.50 \mathrm{mmol} / \mathrm{L}$. The main assumption of the model is that the calcium distribution volume is equal to the extracellular volume during dialysis. This hypothesis is assumed valid if measured and predicted end dialysis plasma water ionized calcium concentrations are equal. A difference between predicted and measured end-dialysis ionized
\end{abstract}

Correspondence to: S. Di Filippo, Division of Nephrology, A. Manzoni Hospital, Via dell’Eremo 9/11, 23900 Lecco, Italy. Email: difilippo.salvatore@libero.it

Conflict of Interest: The Authors have nothing to disclose with regards of the present manuscript.

Disclosure of grants or other funding: None

List of abbreviations: 0-t, Initial and final values; Ca2 +d, Ionized dialysate calcium concentrations (mmol/L); Ca2+di, Dialysate calcium concentration ( $\mathrm{mmol} / \mathrm{L}$ ) at the inlet port of dialyzer; $\mathrm{Ca} 2+\mathrm{MB}$, Intra-dialysis ionized calcium mass balance (mmol); $\mathrm{Ca} 2+$ pw, Ionized plasma water calcium concentrations (mmol/L); Ca2+ pwi, Plasma water calcium concentration (mmol/L) at the inlet port of dialyzer; Ca2+ pwtM, End-dialysis measured plasma water calcium concentration (mmol/L) normalized at pH 7.40; Ca2 + pwtP, End-dialysis plasma water calcium concentration (mmol/L) predicted by the model; Ca2+ pwt(P-M), Difference between end-dialysis plasma water calcium concentration predicted and measured (mmol/L); Ca2+uf, Outlet ultrafiltrate stream calcium concentration (mmol/L) normalized at pH 7.40; CaMB, Intra-dialysis global calcium mass balance (mmol); D'Ca, Calcium dialysance (L/min) corrected for cardiopulmonary and access recirculation; D'cond, Conductivity dialysance (L/ $\mathrm{min}$ ) corrected for cardiopulmonar and access recirculation; KoAcond, "Intrinsic" dialysance for conductivity (mL/min); $\mathrm{MCa} 2+$, Mobilization of calcium from extracellular fluid compartment (mmol); $\mathrm{Na}+\mathrm{d}$, Ionized dialysate sodium concentrations (mmol/L); Na+pw, Ionized plasma water sodium concentrations (mmol/L); Qbi, Inlet blood flow (mL/min); Qei, Inlet blood water flow (mL/min); Qdi, Inlet dialysate flow (mL/min); Cdi, Inlet dialysate conductivity (mS/cm); Qf, Total ultrafiltrate (L); QfECW, Ultrafiltrate removed from the extracellular fluid compartment (L/min); Qpwi, Inlet plasma water flow (L/min); SPVVCaKM, Single-compartment variable-volume calcium kinetic model; SPVV-NaKM, Single-compartment variable-volume sodium kinetic model; Td, Dialysis session duration ( $\mathrm{min}$ ); VCat, End-dialysis calcium distribution volume (L); Vut, End dialysis urea distribution volume (L); spKt/V, Single Pool Kt/N; $\alpha$, Donnan factor 
plasma water calcium concentration is a deviation on our main hypothesis, meaning that a substantial amount of calcium is exchanged between the extracellular volume and a nonmodeled compartment.

Findings: The difference between predicted and measured values was $0.02 \mathrm{mmol} / \mathrm{L}$ (range $-0.08: 0.16 \mathrm{mmol} / \mathrm{L}$ ). With a mean ionized dialysate calcium concentration of $1.25 \mathrm{mmol} / \mathrm{L}$, calcium mass balance was on average negative (mean \pm SD $-0.84 \pm 1.33 \mathrm{mmol}$, range $-5.42: 2.75$ ). Predialysis ionized plasma water concentration and total ultrafiltrate were the most important predictors of calcium mass balance. A significant mobilization of calcium from the extracellular pool to a nonmodeled pool was calculated in a group of patients.

Discussion: The proposed single pool variable-volume Calcium kinetic model is adequate for prediction and quantification of intradialysis calcium mass balance, it can evaluate the eventual calcium transfer outside the extracellular pool in clinical practice.

Key words: Calcium and phosphate metabolism, kinetics, mathematical models

\section{INTRODUCTION}

Management of calcium metabolism in CKD-5D patients is of paramount importance. Although this is a muchdebated topics, little is known with certainty and most of the recent guidelines ${ }^{1}$ are based on experts' opinions. Notably the debate on the optimal concentration of calcium in the dialysate $(\mathrm{d}[\mathrm{Ca}])^{2,3}$ is still open. The optimal $\mathrm{d}[\mathrm{Ca}]$ should prevent severe secondary hyperparathyroidism (SHPT), as well as cardiovascular and soft tissue calcifications. Some authors support the use of a low d[Ca] to reduce the long-term risk of vascular and valvular calcification $^{4,5}$ while others suggest avoiding low $\mathrm{d}[\mathrm{Ca}$ ], because it may favor hypotension, cardiac arrhythmias during hemodialysis (HD) as well as worsen SHPT. ${ }^{6}$ Thus, from the clinical point of view, it is crucial to assess calcium balance during each HD session to tailor the intradialysis balance to the patient needs.

Few incongruent studies yielding conflicting results on intradialytic calcium mass balance (CaMB) have been published and little is known on intradialysis CaMB management. In the context of the DialysIS study (Dialysis therapy between Italy and Switzerland, aimed to improve the personalization of hemodialytic treatments through a modellistic approach), we evaluated the intradialysis CaMB by applying a Single-Pool Variable-Volume Calcium Kinetic Model (SPVV-CaKM) to patients on chronic HD. ${ }^{7}$ Specifically, we investigated the SPVV-CaKM accuracy in predicting the serum calcium at the end of dialysis session. The differences between our proposal and the model suggested by Gotch et al. $^{7}$ are a different set of parameters (Donnan's factor and calcium effective ionic dialysance) and instead of a theoretic approach, the use of real clinical data derived by implementing the model in dialysis patients. The aim of our study is to provide a simple and precise instrument capable of giving an accurate estimate of intradialytic calcium mass balance in a clinical setting.

\section{RESULTS}

\section{Patients' data}

Thirty-four patients (20 males and 14 females, mean age $71.6 \pm 9.7$ years, vintage $71.0 \pm 55.4$ months) on thriceweekly HD were studied during 240 sessions (mean $6.5 \pm 1.9$ for each patient; range 3-9). All patients were dialysed with a nominal $\mathrm{d}[\mathrm{Ca}]$ of $1.50 \mathrm{mmol} / \mathrm{L}$; the prescribed blood flow rate (Qbi) ranged between 150 to $350 \mathrm{~mL} / \mathrm{minutes}$, dialysate flow rate (Qdi) was fixed to $500 \mathrm{~mL} /$ minutes and the treatment time ranged from 3 to 5 hours (Figure 1).

Dialysate $\mathrm{Ca}^{2+}$ concentration at the inlet port of dialyzer $\left(\mathrm{Ca}^{2+} \mathrm{di}\right)$ ranged between 1.16 and $1.35 \mathrm{mmol} / \mathrm{L}$. This wide range of $\mathrm{Ca}^{2+}$ di is a consequence of the individualized dialysate sodium $\left[\mathrm{Na}^{+}\right]$prescription (133.8 \pm 2.6 ; range: 126.6 to $139.6 \mathrm{mmol} / \mathrm{L}$ ) that is obtained through changes in dialysate conductivity (range 13.5 to $14.7 \mathrm{mS} /$ $\mathrm{cm}$; Figure 1). Plasma water ionized calcium concentration at the start of dialysis $\left(\mathrm{Ca}^{2+} \mathrm{pw} 0\right)$ ranged between 1.00 and $1.43 \mathrm{mmol} / \mathrm{L}$, calcium effective ionic dialysance $\left(\mathrm{D}_{\mathrm{Ca}}^{\prime}\right)$ between 69.6 and $188.7 \mathrm{~mL} /$ minutes and calcium distribution volume $\left(\mathrm{V}_{\mathrm{Ca}} \mathrm{t}\right)$ between 6.25 and $15.17 \mathrm{l}$ (Figure 1).

\section{Model's results}

The end dialysis calcium concentration in the plasma water $\left(\mathrm{Ca}^{2+}\right.$ pwtP) was accurately estimated by the singlecompartment variable-volume calcium kinetic model (SPVV-CaKM) illustrated in ${ }^{7}$ and modified as described in 


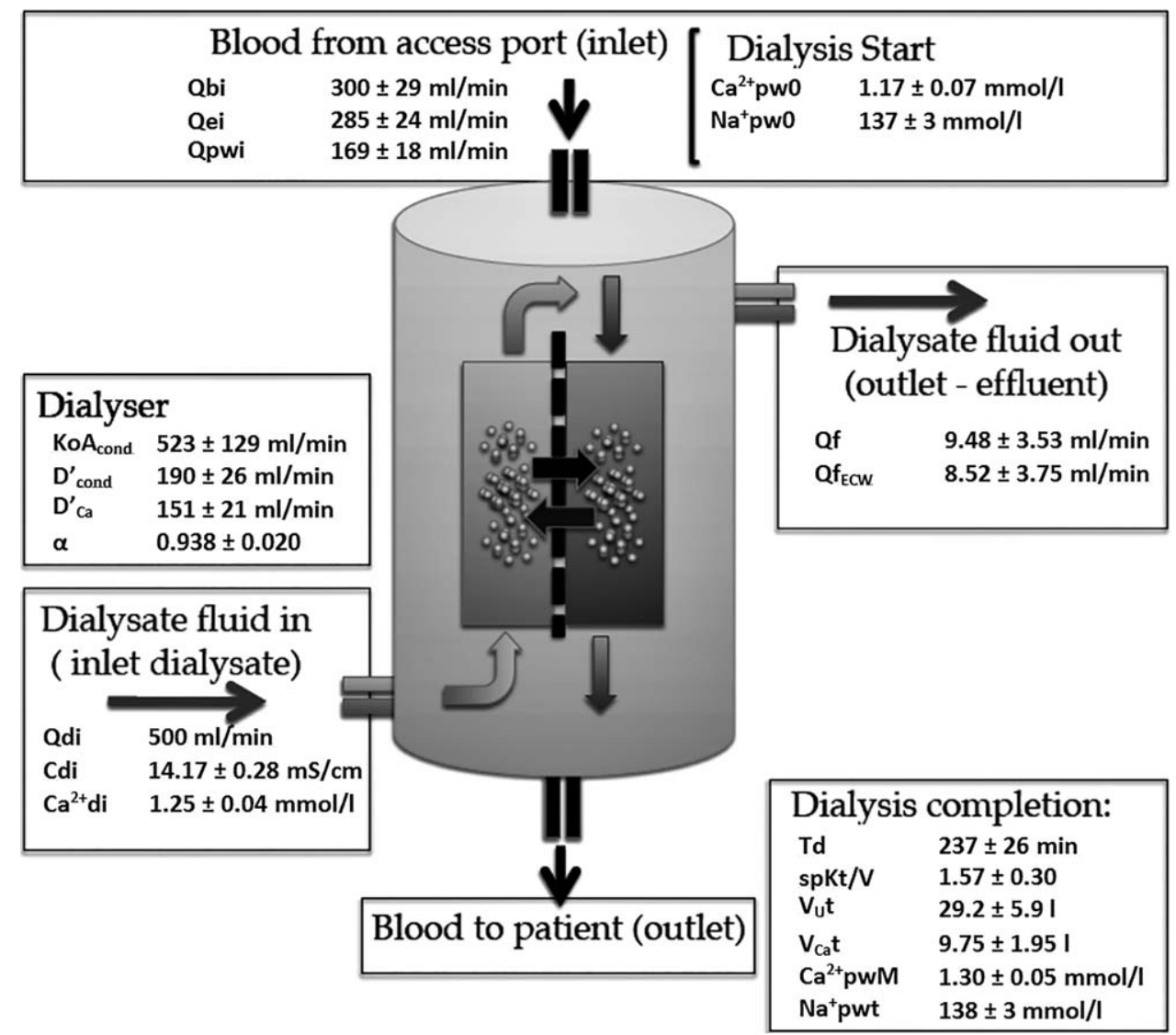

Figure 1 Treatment parameters and input values to SPVV-CaKM (for acronym explanation see List of abbreviations)

the methods. Measured $\left(\mathrm{Ca}^{2+}\right.$ pwtM) and predicted $\left(\mathrm{Ca}^{2+}\right.$ pwtP) values and their difference $\left(\mathrm{Ca}^{2}{ }^{+} \operatorname{pwt}(\mathrm{P}-\mathrm{M})\right)$ are reported in Table 1 . Considering all study participants $(\mathrm{N}=34), \mathrm{Ca}^{2+}$ pwtP and $\mathrm{Ca}^{2+}$ pwtM resulted significantly different $(\mathrm{P}<0.001)$. However, when the measurement error was taken into account, only an absolute value of $\mathrm{Ca}^{2+}$ pwt(P-M) greater than $0.05 \mathrm{mmol} / \mathrm{L}$ was assumed as evidence of exchange toward a nonmodeled compartment. Hence, dialysis sessions were divided into two groups: Group 1 (no calcium flux from the extracellular compartment), absolute $\mathrm{Ca}^{2+}$ pwt $(\mathrm{P}-\mathrm{M}) \leq 0.05 \mathrm{mmol} / \mathrm{L}$; Group 2 (calcium flux from the extracellular compartment), absolute $\mathrm{Ca}^{2+} \operatorname{pwt}(\mathrm{P}-\mathrm{M})>0.05 \mathrm{mmol} / \mathrm{L}$. Group 1 included 192 sessions ( $80 \%$ of all sessions) performed in 29 patients. In this group, the difference between $\mathrm{Ca}^{2+}$ pwtP and $\mathrm{Ca}^{2+}$ pwtM was not statistically significant (Table 1 ) and no relationship between $\mathrm{Ca}^{2+}$ pwt(P-M) and $\mathrm{Ca}^{2+}$ pwtM was noted. Figure 2 depicts the mean value of each patient's $\mathrm{Ca}^{2+}$ pwt(P-M) plotted against the mean value of $\mathrm{Ca}^{2+}$ pwtM in group 1 . The difference from zero was symmetrically distributed and there was no specific pattern related to $\mathrm{Ca}^{2+}$ pwtM.
Conversely, Group 2 included the remaining 48 sessions performed in 8 patients. In this group, $\mathrm{Ca}^{2+}$ pwtP was significantly greater than $\mathrm{Ca}^{2+}$ pwtM (Table 1 ) suggesting calcium exchange with nonmodeled compartments. Global calcium mass balance $\left(\mathrm{Ca}^{2+} \mathrm{MB}\right)$, was on average negative $(-0.83 \pm 1.33 \mathrm{mmol})$ due to a larger convective calcium flux $(2.69 \pm 1.21 \mathrm{mmol})$ from the patient to the dialysate compared to the diffusive calcium flux $(1.86 \pm 0.91 \mathrm{mmol})$ from the dialysate to the patient. However, a considerable patient-to-patient as well as intrapatient variability was present. When individual patients were considered, 26 exhibited a negative $\mathrm{Ca}^{2+}$ $\mathrm{MB}(-1.23 \pm 0.84 \mathrm{mmol})$ while 8 patients showed a positive $\mathrm{Ca}^{2+} \mathrm{MB}(0.70 \pm 0.47 \mathrm{mmol}$; Figure 3).

Compared to patients with negative $\mathrm{Ca}^{2+} \mathrm{MB}$, individuals with positive $\mathrm{Ca}^{2+} \mathrm{MB}$ showed a significantly lower levels of serum calcium at dialysis start $\left(\mathrm{Ca}^{2+} \mathrm{pw} 0\right.$ : $1.12 \pm 0.06$ vs. $1.19 \pm 0.07 \mathrm{mmol} / \mathrm{L} ; \mathrm{P}<0.01)$ and a significantly lower total ultrafiltrate volume (Qf: $1.8 \pm 0.9$ vs. $2.4 \pm 0.7 \mathrm{l} ; \mathrm{P}<0.05)$. No significant differences were found in $\mathrm{Ca}^{2+} \mathrm{di}, \mathrm{D}_{\mathrm{Ca}}^{\prime}$ and $\mathrm{Td}$ values, suggesting that a positive 


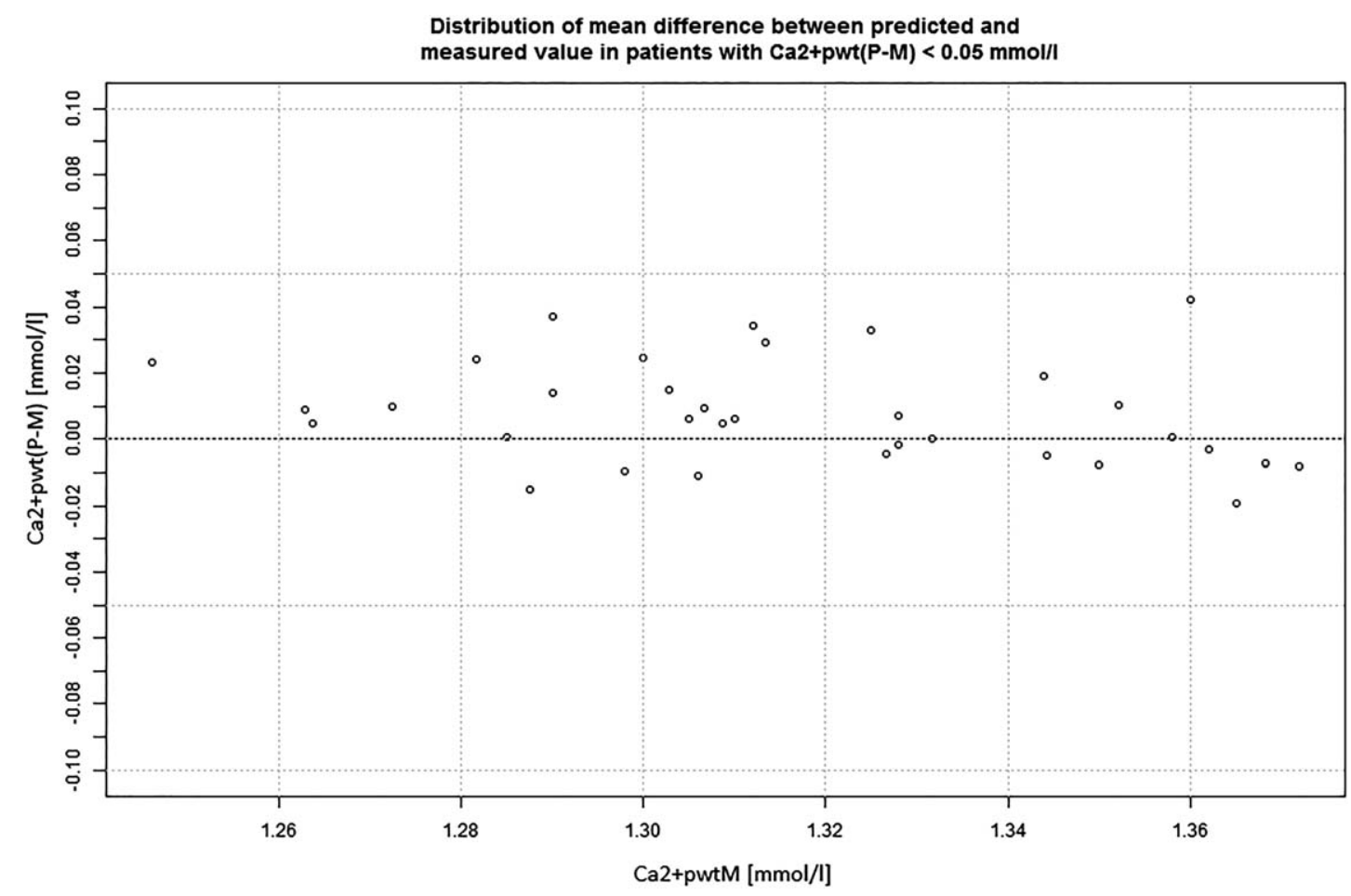

Figure 2 Distribution of mean difference between predicted and measured value in patients with $\mathrm{Ca} 2^{+}$pwt $(\mathrm{P}-\mathrm{M})<0.05 \mathrm{mmol} / \mathrm{L}$.

$\mathrm{Ca}^{2+} \mathrm{MB}$ was supported by a greater diffusive (from dialysate to patient: $2.00 \pm 0.86$ vs. $1.49 \pm 0.70 \mathrm{mmol}$; $\mathrm{P}<0.001$ in Group 2 and 1, respectively) calcium flux, driven by a greater concentration gradient $\left(\mathrm{Ca}^{2+} \mathrm{di}-\mathrm{Ca}^{2+}\right.$ pw0: $0.14 \pm 0.07$ vs. $0.06 \pm 0.07 \mathrm{mmol} / \mathrm{L} ; \mathrm{P}<0.001)$ and smaller convective (from patient to dialysate) calcium flux. The opposite was true in case of negative $\mathrm{Ca}^{2+} \mathrm{MB}$.

We interpreted the difference between predicted and measured end-dialysis ionized plasma water calcium concentration as an error in the main hypothesis. So, if the predicted plasma water ionized calcium concentration is different from the measured value, it means that there is an exchange of calcium from the extracellular compartment toward a nonmodeled compartment. We defined this exchange as sequestration or mobilization $\left(\mathrm{MCa}^{2+}, \mathrm{mmol}\right)$, as in. ${ }^{7}$

As expected, a significant sequestration of $\mathrm{Ca}^{2+}$ from extracellular fluid compartment $\left(\mathrm{MCa}^{2+}\right)$ was noted in Group $2(0.69 \pm 0.31 \mathrm{mmol}$ vs. $0.08 \pm 0.31 \mathrm{mmol}$, $\mathrm{P}<0.001$, in Group 2 and 1, respectively).

Finally, we verified whether bone remodelling, as estimated by PTH values, could affect $\mathrm{Ca}^{2+} \mathrm{MB}{ }^{8}$ Patients were divided into two groups according to PTH levels less than two times the upper values of normality $(130 \mathrm{pg} / \mathrm{mL})$ or more than nine times the upper values of normality ( 585 $\mathrm{pg} / \mathrm{mL}$ ). Eleven patients showed PTH levels > $585 \mathrm{pg} / \mathrm{mL}$;

Table 1 Mean values of predicted and measured end dialysis plasma water ionized calcium concentration and their difference

\begin{tabular}{lccccc}
\hline No. of sessions & No. of pts & $\begin{array}{c}\mathrm{Ca}^{2+} \mathrm{pwtP} \\
(\mathrm{mmol} / \mathrm{L})\end{array}$ & $\begin{array}{c}\mathrm{Ca}^{2+} \mathrm{pwtM} \\
(\mathrm{mmol} / \mathrm{L})\end{array}$ & $\begin{array}{c}\mathrm{Ca}^{2+} \mathrm{pwt} \\
(\mathrm{P}-\mathrm{M})(\mathrm{mmol} / \mathrm{L})\end{array}$ & \multicolumn{1}{c}{$\mathrm{P}$} \\
\hline 240 & 34 & $1.33 \pm 0.02$ & $1.30 \pm 0.05$ & $0.02 \pm 0.04$ & $<0.001$ \\
192 & Group 1 29 & $1.32 \pm 0.04$ & $1.31 \pm 0.04$ & $0.01 \pm 0.03$ & NS \\
48 & Group2 8 & $1.35 \pm 0.04$ & $1.28 \pm 0.05$ & $0.08 \pm 0.03$ & $<0.001$ \\
\hline
\end{tabular}

Group 1: patients with $\mathrm{Ca}^{2+}$ pwt $(\mathrm{P}-\mathrm{M})<0.05 \mathrm{mmol} / \mathrm{L}$.

Group 2: patients with $\mathrm{Ca}^{2+}$ pwt $(\mathrm{P}-\mathrm{M}) \geq 0.05 \mathrm{mmol} / \mathrm{L}$. 


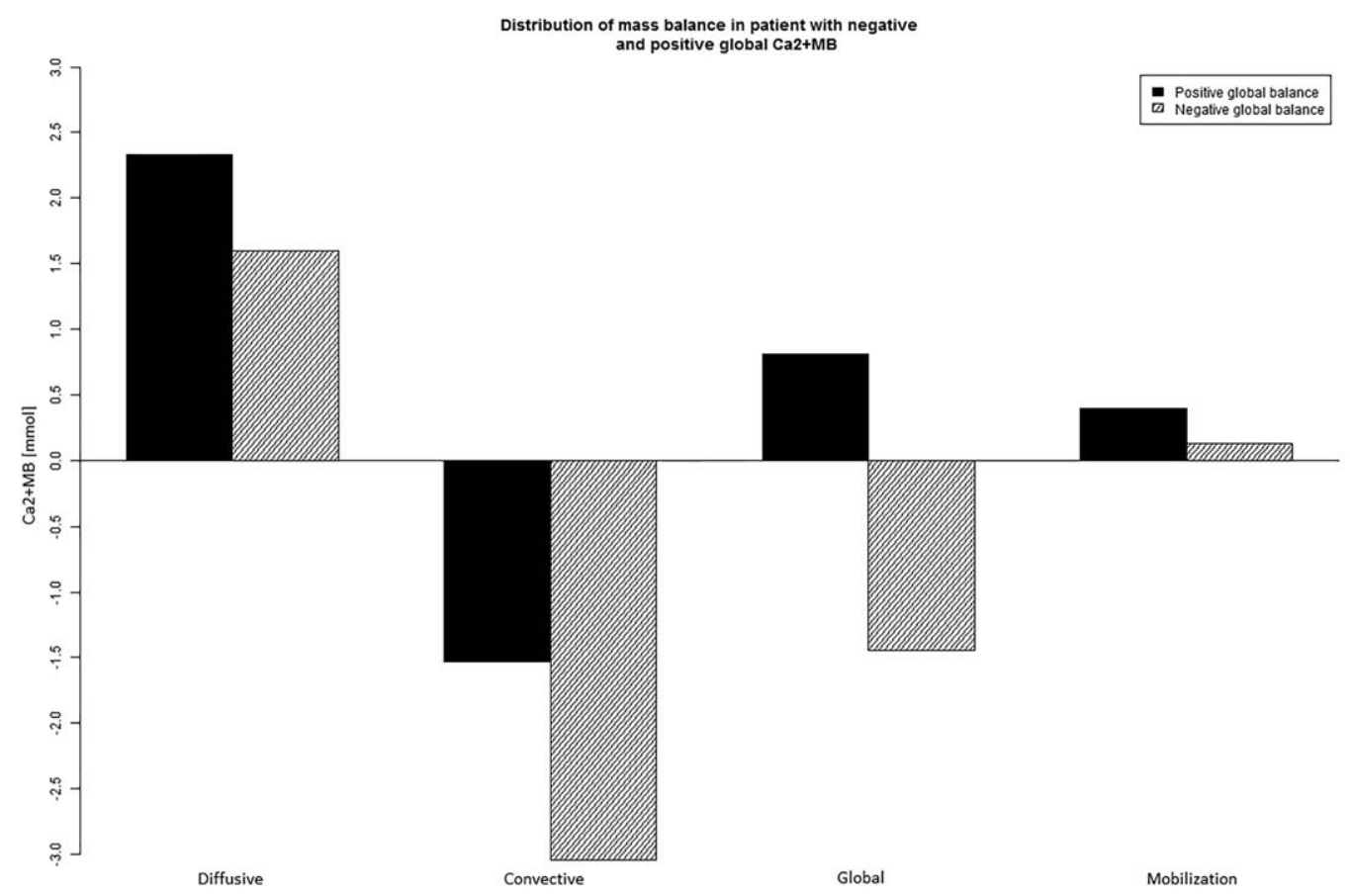

Figure 3 Distribution of mass balance in patients with negative and positive global $\mathrm{Ca} 2^{+} \mathrm{MB}$.

6 patients showed PTH levels $<130 \mathrm{pg} / \mathrm{mL} ; 3$ patients exhibited a reduction from high to normal levels during cinacalcet treatment (Table 2).

\section{DISCUSSION}

The optimal $\mathrm{d}[\mathrm{Ca}]$ choice has important implications in preventing or at least reducing renal bone disease, cardiovascular calcifications and intradialytic arrhythmias and hypotensions in HD patients. However, how to manipulate the intradialysis calcium balance to achieve these results is still an unanswered question.
Very few incongruent studies on intradialysis CaMB have been published so far. $^{8-11}$ The inconsistencies found in these studies can be explained by the chosen method of CaMB estimation. All of these studies quantified CaMB collecting the total effluent dialysate to measure total calcium concentration. With this procedure, even a low imprecision in the analytical method to assess [Ca] might induce a substantial CaMB calculation error. Total calcium is most frequently measured using spectrophotometry and the o-cresolphthalein complexone dye. According to a within-run per cent coefficient of variation of 2.5, the maximum standard deviation with

Table $2 \mathrm{Ca}^{2+} \mathrm{MB}$ (mmol) values according to predialysis PTH levels

\begin{tabular}{lccc}
\hline & PTH $<2 * 65 \mathrm{pg} / \mathrm{mL}(\mathrm{n}=6)$ & $\mathrm{PTH}>9 * 65 \mathrm{pg} / \mathrm{mL}(\mathrm{n}=11)$ & $\mathrm{P}$ \\
\hline PTH-0 $(\mathrm{pg} / \mathrm{mL})$ & $92 \pm 34$ & $811 \pm 221$ & $<0.001$ \\
PTH-t $(\mathrm{pg} / \mathrm{mL})$ & $62 \pm 35$ & $554 \pm 256^{*}$ & $<0.001$ \\
Global Ca ${ }^{2+} \mathrm{MB}(\mathrm{mmol})$ & $-0.73 \pm 1.56$ & $-1.26 \pm 1.85$ & $\mathrm{NS}$ \\
Diffusive Ca ${ }^{2+} \mathrm{MB}(\mathrm{mmol})$ & $1.88 \pm 0.61$ & $1.56 \pm 0.64$ & $\mathrm{NS}$ \\
Convective Ca $^{2+} \mathrm{MB}(\mathrm{mmol})$ & $2.61 \pm 1.38$ & $2.83 \pm 1.71$ & $\mathrm{NS}$ \\
$\mathrm{Mca}^{2+}(\mathrm{mmol})$ & $0.10 \pm 0.27$ & $0.16 \pm 0.45$ & $\mathrm{NS}$ \\
$\mathrm{Ca}^{2+} \mathrm{pwO}(\mathrm{mmol} / \mathrm{L})_{\mathrm{Qf}(\mathrm{l})}$ & $1.16 \pm 0.09$ & $1.18 \pm 0.08$ & $\mathrm{NS}$ \\
\hline
\end{tabular}

PTH $=$ Parathyroid hormone.

$* \mathrm{P}=0.02$ vs. predialysis values. 


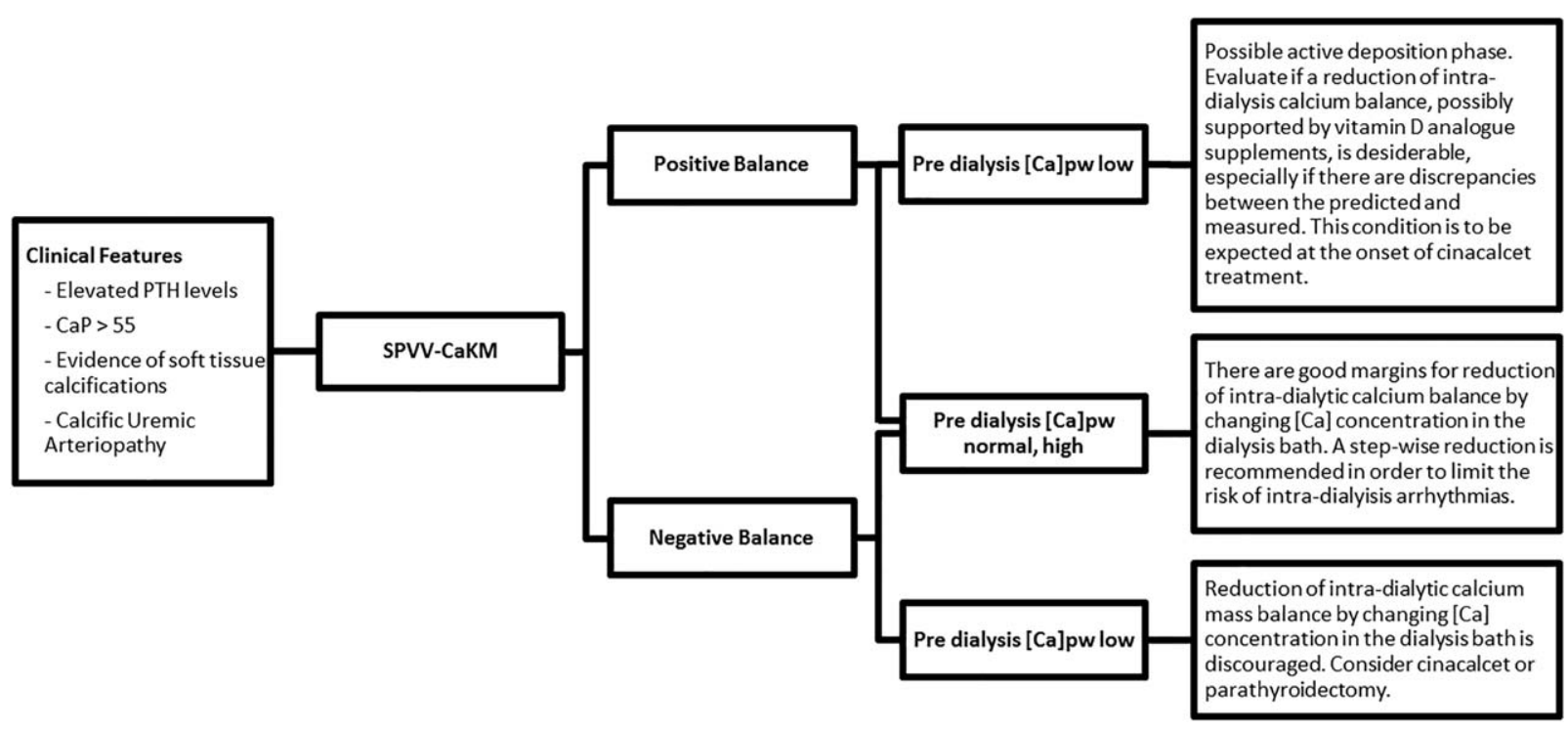

Figure 4 Clinical applications of SPVV-CaKM. Ionized calcium plasma water concentration is considered low when $\geq 0.95$ $\mathrm{mmol} / \mathrm{L}$ and $<1.1 \mathrm{mmol} / \mathrm{L}$, normal when $\geq 1.1$ and $<1.25 \mathrm{mmol} / \mathrm{L}$ high when $\geq 1.25 \mathrm{mmol} / \mathrm{L}$

dialysate $[\mathrm{Ca}]$ of $1.25 \mathrm{mmol} / \mathrm{L}$ maybe as large as $0.03 \mathrm{mmol} / \mathrm{L}$. Considering a total of $90-120 \mathrm{~L}$ of dialysate per dialysis session, this apparently negligible imprecision may lead to a substantial error in the intradialysis CaMB estimation.

It is well known that alkalosis reduces $\left[\mathrm{Ca}^{2+}\right]$ solubility. ${ }^{12}$ Hence, ionized calcium based methods ${ }^{11}$ may overestimate $\mathrm{CaMB}$ if $\mathrm{pH}$-mediated variation in ionized calcium concentration are not appropriately accounted.

The inconsistences found in these papers led us to raise some questions about the proposed methodological approach and to choose a modellistic solution, based on the one previously described by Gotch, ${ }^{7}$ capable of overcome these difficulties. In this study, intradialysis $\mathrm{Ca}^{2+}$ $\mathrm{MB}$ was determined by a single-compartment variablevolume kinetic model enabling calculation of $\mathrm{Ca}^{2+}$ content in the extracellular fluid compartment from the start to the end of each dialysis session. Prerequisites to use this method are the accurate estimation of the Donnan coefficient ( $\alpha$ factor) and of the "effective" calcium dialysance. The $\alpha$ factor, we used in our study was obtained by the ratio between ultrafiltrate and inlet blood stream ionized calcium concentrations with ultrafiltrate values normalized at $\mathrm{pH} 7.40$, because ultrafiltrate ionized calcium values are also $\mathrm{pH}$ dependent. ${ }^{13}$

We derived the "effective" calcium dialysance from the conductivity dialysance obtained from the Diascan ${ }^{\circledR}$ module (Baxter Gambro Dasco Spa, Medolla MO). The mean value of repeated conductivity dialysances using a singlestep conductivity profile, as Diascan $₫$ does, may be considered an adequate estimate of urea clearance corrected for total recirculation. ${ }^{14}$ We considered the calcium dialysance similar to the urea dialysance, given the similar molecular weight of urea and calcium. These are considered small molecules $(<200 \mathrm{u})$, thus having similar diffusive proprieties, without considering electric charge. The dialyzer mass transfer coefficient per area may be considered similar between the two compounds and the difference between the two dialysance can be considered expression of the different effective flows (blood water for urea and plasma water for calcium).

Most of our patient using a nominal dialysate [Ca] of $1.50 \mathrm{mmol} / \mathrm{L}$ showed a neglectable difference between measured and predicted end-dialysis plasma water ionized calcium concentration suggesting that the model is accurate, it allows a dialysis calcium mass balance estimation and it may guide individualized $\mathrm{d}[\mathrm{Ca}]$ prescription.

The fact that $\mathrm{Ca}^{2+}$ pwt(P-M) was, in some patients, significantly different from zero $(\mathrm{P}<0.001)$ suggests the existence of a calcium flux from the extracellular compartment to a not modeled pool. In particular, three patients who experienced dialysis sessions with $\mathrm{Ca}^{2+}$ pwt(P$\mathrm{M}) \leq 0.05 \mathrm{mmol} / \mathrm{L}$ and later on experienced dialysis sessions with $\mathrm{Ca}^{2+}$ pwt $(\mathrm{P}-\mathrm{M})>0.05 \mathrm{mmol} / \mathrm{L}$. A post hoc review of patients' chart revealed that in all three patients this phenomenon occurred when treatment with cinacalcet was started, suggesting that our method may be able to catch the effect of treatment on calcium balance during dialysis. Of course, this intriguing hypothesis needs confirmation in a larger specifically designed study. 
The actual distribution volume of calcium during dialysis is not known, but several authors ${ }^{7,15-17}$ pointed out that, when the different compartment involved in calcium metabolism are in dynamic-equilibrium, the extracellular volume could be a fair approximation of the distribution volume of calcium. The good agreement between the end dialysis $\mathrm{Ca}^{2+}$ concentration predicted by the model and the measured value support this hypothesis under certain conditions.

Since a precise measurement of the rapidly exchangeable $\mathrm{Ca}$ pool and the other compartments that may be involved in calcium kinetics cannot be made in a simple and direct manner during the clinical routine, adding to the SPVV-CaKM compartments that cannot be modeled can only lead to imprecision and confusion. From this particular vantage point, a single-pool model represents an acceptable simplification, with a high degree of accuracy and ready-to-use when the underlying hypothesis are confirmed. In the minority of studied patients, in which our model predictions were significantly different from collected data, other compartments may come into play, but it is still an open question, outside the scope of the present study, whether and how different factors may contribute to modify the equilibrium between all the compartments possibly involved in calcium homeostasis.

We observed a significant decrease in PTH plasma levels in all the patients regardless of the Ca mass balance (negative in $76 \%$ patients and positive in the remaining $24 \%$ ) supporting the hypothesis that parathyroid glands respond primarily to the increase in $\mathrm{Ca}^{2+}$ pw secondary to the diffusive flux from the dialysate to the patient as it was the case in our population. We could not find any significant relationship between PTH levels outside the suggested target range (2-9 times the upper reference limit for the assay) ${ }^{1}$ and global, diffusive, or convective $\mathrm{Ca}^{2+} \mathrm{MB}$, possibly due to the low number of patients with (Table 2). A decreased diffusive $\mathrm{Ca}^{2+} \mathrm{MB}$ may account for the negative to positive $\mathrm{Ca}^{2+} \mathrm{MB}$ transition observed in patients that initiated cinacalcet in the course of the study recordings since this drug modify the calcium/PTH set point and increases the blood-dialysate calcium gradient. Our results also suggest that factors such as sodium dialysate profiling commonly used in daily practice may substantially change the "nominal" concentration of calcium in dialysate. This observation may contribute to explain the apparent discrepancy of our results with previous ones since the real calcium concentration is often lower than the "nominal" calcium concertation reported in the dialysate bags.

At the present time, there is not a consensus on the proper management of calcium in CKD-5D patients, mostly because the pathogenesis and progression of many mineral-related disorders (e.g., coronary calcifications, calcific uremic arteriopathy) are not completely understood. The presented kinetic model is a valid instrument when dealing with this complex and multifaceted problem and it has several advantage on the calcium mass balance performed with total or partial dialysate collection, namely the ease of use in routine clinical practice, the ability to predict the end dialysis plasma water calcium concentration when different calcium concentrations in the dialysate are used and the prediction of calcium that will not appear in the extracellular volume $\left(\mathrm{MCa}^{2+}\right)$, with the risk of calcium complexes deposition. In Figure 4, we propose a practical use of the SPVV-CaKM in clinical routine, without presumption of completeness. If these results will be confirmed by other large studies a nomogram-like approach may also be feasible for a routine evaluation of $\mathrm{Ca}^{2+} \mathrm{MB}$.

This instrument may also provide a common basis for classifying the patients: as the model takes in considerations several parameters to estimate calcium balance, classifying patients based on the estimated balance could avoid important confounders and thus improve accuracy and reliability of calcium homeostasis studies in CKD-5D patients.

The main limitations of this study are the relatively small sample size and the fact that all study subjects received dialysis with a nominal calcium concentration of $1.50 \mathrm{mmol} / \mathrm{L}$ in the dialysate. The presented model is based on several hypotheses, many of them are difficult to prove rigorously, and it needs further validation, including a dedicated study comparing the model's performance with different calcium dialysate concentrations $(1.25,1.50$, and $1.75 \mathrm{mmol} / \mathrm{L})$ and use of drugs that interfere with bone metabolism (e.g., cinacalcet). However, the rigorous methodology and the wide range of ionized calcium concentrations in the dialysate utilized are in our opinion the strengths of current findings. In conclusions, current results suggest that it is feasible to estimate the intradialysis global calcium balance using a singlecompartment variable-volume calcium kinetic model (SPVV-CaKM). Furthermore, this study shows that using a fixed nominal dialysate calcium concentration (1.50 mmol/ $\mathrm{L}), \mathrm{Ca}^{2+} \mathrm{MB}$ can vary widely not only between patients but even in the same patient, according to its pharmacological treatment. Our data corroborates the notion that global $\mathrm{Ca}^{2+} \mathrm{MB}$ depends not only on $\mathrm{d}[\mathrm{Ca}]$ but also on predialysis plasma water calcium $\left[\mathrm{Ca}^{2}+\right.$ pwo] total ultrafiltration and bone metabolism. Therefore, it is unlikely that one dialysate calcium concentrations may be adequate for all the patients. This is particularly true considering the great variability in the patient drug prescription for serum PTH, calcium, and phosphate management. An integrated approach that encompasses all these factors is needed for a personalized $\mathrm{d}[\mathrm{Ca}$ prescription. In this view, the presented model offer 
to the practising nephrologists an accurate view of what is going on during dialysis, such as convective removal, diffusive exchanges and quantity of calcium that will not appear in the extracellular fluid, thus possibly improving the management of calcium metabolism in CKD-5D patients.

\section{MATERIALS AND METHODS}

\section{Experimental design}

All patients, after signing the informed consent form, have been monitored for a minimum of 3 dialysis sessions. During each monitored session, several parameters has been recorded:

- Dialysis' duration and total ultrafiltration

- Blood samples for the evaluation of ionized plasma water calcium and sodium concentrations, $\mathrm{pH}$, urea, albumin, and PTH concentrations both at the start and at the end of the treatment. The end-dialysis sample has been acquired after reduction of blood flow to $50 \mathrm{~mL} /$ minutes for 3 minutes

- Dialysate sample for the determination of ionized calcium and sodium concentrations, collected from the prefilter dialysate port thirty minutes after session's start

- Conductivity Dialysance and blood flow values through the entire session

\section{Calcium modeling}

The main hypothesis of the adopted model is that the calcium distribution volume is equal to extracellular volume, which means that, at least during dialysis treatment, there is no net exchange between the extracellular volume and other compartments.

Intradialysis $\mathrm{Ca}^{2+} \mathrm{MB}$ was defined as the change in $\mathrm{Ca}^{2+}$ content in the extracellular fluid volume during a dialysis session and calculated according to Equation 2 reported in the Appendix.

All dialysis sessions were performed with Gambro Artis ${ }^{\mathrm{TM}}$ machine equipped with Diascan ${ }^{\circledR}$ module for automatic determination of "effective" conductivity dialysance that is conductivity dialysance corrected for cardiopulmonary and access recirculation $\left(\mathrm{D}^{\prime}\right.$ cond $) .{ }^{14}$

End-dialysis urea distribution volume $\left(\mathrm{V}_{\mathrm{U}} \mathrm{t}\right)$ was determined using $\mathrm{D}^{\prime}$ cond as input to the 3-point single-pool variable-volume urea kinetic model. ${ }^{18,19} \mathrm{~V}_{\mathrm{U}}$ was used to estimate end-dialysis calcium distribution volume $\left(\mathrm{V}_{\mathrm{Ca}} \mathrm{t}\right)$ defined as anatomically equal to the extracellular fluid volume and about $1 / 3$ of $\mathrm{V}_{\mathrm{u}} \mathrm{t}$. $\mathrm{D}^{\prime}$ cond was also used to calculate in vivo "intrinsic dialysance" for conductivity $\left(\mathrm{KoA}_{\text {cond }}\right)$ from which calcium dialysance $\left(\mathrm{D}_{\mathrm{ca}}^{\prime}\right)$ was derived. ${ }^{20}$

A Donnan's factor $(\alpha)$ of 0.938 , obtained from previously unpublished data on a HDF technique, Hemo-Filtrate Reinfusion (HFR) able to achieve diffusion and convection separately through two filters in series, ${ }^{21}$ was used to account for the amount of plasma water diffusible $\mathrm{Ca}^{2}$.

Finally, the ultrafiltration rate from extracellular volume ( $\mathrm{Qf}_{\mathrm{ECW}}$ ) was obtained by the ratio between intradialysis sodium balance, estimated according to singlecompartment variable-volume sodium kinetic model $(\text { SPVV-NaKM })^{22,23}$ and the mean value between initial $\left(\mathrm{Na}^{+}\right.$pw0) and final plasma water $\mathrm{Na}^{+}$concentrations $\left(\mathrm{Na}^{+}\right.$pwt).

Equation 2 accounts for both diffusive and convective components of calcium flux. Based on the assumptions of single compartment kinetic models, the convective part is expressed by the ultrafiltration from the hypothesized distribution volume, while the diffusion components are dependent on concentration gradient between dialysate and plasma, Donnan's equilibrium and clearance of the studied molecule.

The difference between end-dialysis ionized plasma water calcium concentration predicted by the kinetic model $\left(\mathrm{Ca}^{2+} \mathrm{pwtP}\right)$ and measured value normalized to $\mathrm{pH} 7.40$ $\left(\mathrm{Ca}^{2+}\right.$ pwtM $)$ was considered the most useful variable for validating the kinetic model. Predicted values were calculated according to Equation 3, obtained from Equation 2.

Main variables needed for applying Equation 3 were:

- calcium Donnan's factor $(\alpha)$;

- initial ionized plasma water calcium concentration $\left(\mathrm{Ca}^{2+} \mathrm{pw} 0\right)$

- ionized dialysate calcium concentration $\left(\mathrm{Ca}^{2+} \mathrm{di}\right)$;

- initial and final calcium distribution volume $\left(\mathrm{V}_{\mathrm{ca}} \mathrm{O}, \mathrm{V}_{\mathrm{ca}} \mathrm{t}\right)$;

- calcium dialysance ( $\mathrm{D}^{\prime}$ ca);

- ultrafiltration rate from extracellular water $\left(\mathrm{Qf}_{\mathrm{ECW}}\right)$;

- plasma water flow rate $\left(\mathrm{Q}_{\mathrm{pwi}}\right)$.

Global, diffusive and convective $\mathrm{Ca}^{2+} \mathrm{MB}$ were calculated according to Equations 5, 6, and 7 and sequestration of calcium $\left(\mathrm{MCa}^{2+}\right)$ outside the extracellular fluid compartment was calculated according to Equation 4.

All electrolytes' concentrations and $\mathrm{pH}$ values were obtained using direct ionometry: Stat Profile®CCX analyser, Nova Biomedical, Waltham, USA; within-run imprecision for $\mathrm{Ca}^{2+}: 2 \% \pm 0.05 \mathrm{mmol} / \mathrm{L}^{24}$ To account for the changes in $\mathrm{pH}$ values which is known to affect $\mathrm{Ca}^{2+}$ concentrations, ${ }^{13}$ end of dialysis $\mathrm{Ca}^{2+}$ pw and $\mathrm{Ca}^{2+}$ uf values were normalized to the $\mathrm{pH}$ value of 7.40 according to Equation 1 reported in Appendix. 


\section{Statistical analysis}

Continuous variables are reported as means $\pm S D$ and compared with Student's t-test. Variables with a nonnormal distribution are reported as median (range) and analysed by the Wilcoxon or Mann-Whitney test.

The difference between $\mathrm{Ca}^{2+}$ pwtP and $\mathrm{Ca}^{2+}$ pwtM values was considered the most useful variable for validating the kinetic model. Central tendency and dispersion of this difference were used to evaluate the accuracy and precision of the model, respectively. Finally, the adequacy of the model for the entire spectrum of $\mathrm{Ca}^{2+}$ pwtM values was evaluated by plotting the individual differences of $\mathrm{Ca}^{2+}$ pwtP and $\mathrm{Ca}^{2+}$ pwtM against $\mathrm{Ca}^{2+}$ pwtM (similar to a Bland-Altman plot). All analysis was performed using $\mathrm{R}$ version 3.2.0; P-values $<0.05$ were considered significant.

\section{ACKNOWLEDGMENTS}

Portions of this work were presented in abstract form at the Annual Meeting of the American Society of Nephrology in Philadelphia in November 2014 and to the 52 ${ }^{\circ}$ ERA-EDTA congress. The following institutions participated in the DialysIS study: Nephrology and Dialysis, A. Manzoni Hospital, Lecco, Italy; Nephrology and Dialysis, Regional Hospital of Lugano, Lugano, Switzerland; Nephrology and Dialysis, Sant'Anna Hospital, Como, Italy; Nephrology and Dialysis, Hospital and Macchi Foundation, Varese; Chemistry, Material and Chemical Engineering, Politecnico di Milano, Milano, Italy; Management Engineer, Politecnico di Milano, Milano, Italy.

Manuscript received July 2016; revised November 2016.

\section{REFERENCES}

1 Kidney Disease: Improving Global Outcomes (KDIGO) CKD-MBD Work Group. Clinical practice guidelines for the diagnosis, evaluation, prevention and treatment of chronic kidney disease-mineral and bone disorder (CKD-MBD). Kidney Int. 2009; 76(Suppl 113): S1-130.

2 Gotch FA. Pro/Con debate: The calculation on calcium balance in dialysis lowers the dialysate calcium concentrations (pro part). Nephrol Dial Transplant. 2009; 24:2994-2996.

3 Drüeke TB, Touam M. Calcium balance in haemodialysis-do not lower the dialysate calcium concentration too much (con part). Nephrol Dial Transplant. 2009; 24:2990-2993.

4 Ok E, Asci G, Bayraktaroglu S, et al. Reduction of dialysate calcium level reduces progression of coronary artery calcification and improves low bone turnover in patients on hemodialysis. J Am Soc Nephrol. 2016; 27:2475-2486.

5 Gotch FA, Kotanko P, Thijssen S, et al. KDIGO guidelines for dialysate calcium will result in an increased incidence of calcium accumulation in hemodialysis patients. Kidney Int. 2010; 78:343-350.

6 Argiles A, Mion CM. Low-calcium dialysate worsens secondary hyperparathyroidism. J Am Soc Nephrol. 1996; 7:635-636.

7 Gotch F, Kotanko P, Handelman G, Levin N. A kinetic model of calcium mass balance during dialysis therapy. Blood Purif. 2007; 25:139-149.

8 Karohl C, Paschoal JP, Martins de Castro MC, et al. Effects of bone remodelling on calcium mass transfer during haemodialysis. Nephrol Dial Transplant. 2010; 25:1244-1251.

9 Hou SH, Zhao J, Ellman CF, et al. Calcium and phosphorus fluxes during hemodialysis with low calcium dialysate. Am J Kidney Dis. 1991; 18:217-224.

10 Basile C, Libutti P, Di Turo AL, et al. Effect of dialysate calcium concentrations on parathyroid hormone and calcium balance during a single dialysis session using bicarbonate hemodialysis: A crossover clinical trial. Am J Kidney Dis. 2012; 57:92-101.

11 Bosticardo GM, Malberti F, Basile C, et al. Optimizing the dialysate calcium concentration in bicarbonate haemodialysis. Nephrol Dial Transplant. 2012; 27:2489-2496.

12 Argiles A. Points to remember when selecting dialysate calcium concentration. Nephrol Dial Transplant. 1995; 10:451-454.

13 Moore EW. Ionized calcium in normal serum, ultrafiltrates and whole blood determined by ion-exchange electrodes. J Clin Invest. 1970; 49:318-334.

14 Di Filippo S, Pozzoni P, Manzoni C, et al. Relationship between urea clearance and ionic dialysance determined using a single-step conductivity dialysance. Kidney Int. 2005; 68:2389-2395.

15 Rich C. The distribution of calcium given to human subjects by sustained intravenous infusion. J Clin Endocrinol Metab. 1960; 20: 147-156.

16 Fogh-Andersen N, Altura BM, Altura BT, SiggaardAndersen O. Composition of interstitial fluid. Clin Chem. 1995; 41: 1522-1525.

17 Nordin B, et al. Calcium, Phosphate and Magnesium Metabolism. Clinical Physiology and Diagnostic Procedures. Edinburgh, UK: Churchill Livingstone; 1976.

18 Gotch FA. Kinetic modeling in hemodialysis, In: Clinical Dialysis. [Appleton \& Lange]. 1992; 118-146.

19 Di Filippo S, Manzoni C, Andrulli S, et al. Ionic dialysance allows an adequate estimate of urea distribution volume in hemodialysis patients. Kidney Int. 2004; 66: 786-791.

20 Daugirdas JT, Depner TA. A nomogram approach to hemodialysis urea modeling. Am J Kidney Dis. 1994; 23:33-40. 
21 Ghezzi PM, Gervasio R, Tessore V, et al. Hemodiafiltration without replacement fluid: Experimental study. Trans Am Soc Artif Intern Organs. 1992; 38:61-65.

22 Gotch FA, Lam MA, Prowitt M, Keen M. Preliminary clinical results with sodium-volume modeling of hemodialysis therapy. Proc Dial Transplant Forum. 1980; 10:12
23 Di Filippo S, Corti M, Andrulli S, et al. Determining the adequacy of sodium mass balance in hemodialysis using a kinetic model. Blood Purif. 1996; 14:431-436.

24 Stat Profile ${ }^{\circledR}$ Critical Care Xpress. (Nova Biomedical). Retrieved January 23, 2017, from http://www.norahanltd. com/index_files/CCXEN.pdf

\section{APPENDIX : EQUATIONS USED TO ASSESS CALCIUM MASS BALANCE}

Equation 1: Normalization of end-dialysis measured plasma water ionized calcium concentrations:

$$
\mathrm{Ca}^{2+} \mathrm{pwtM}=10^{\left(\log _{10}\left(\mathrm{Ca}^{2+} \mathrm{pwt}\right)-0.24 \cdot(7.40-\mathrm{pHt})\right)}
$$

Legend: $\mathrm{Ca}^{2+}$ pwt and pHt: end-dialysis plasma water ionized calcium concentrations and $\mathrm{pH}$ as determined by direct ionometry.

Equation 2: Change in $\mathrm{Ca}^{2+}$ content in the extracellular fluid volume

$$
\mathrm{d}\left(\mathrm{Ca}^{2+} \mathrm{pw} \cdot \mathrm{VCa}\right) / \mathrm{dt}=\mathrm{D}_{\mathrm{Ca}} \cdot\left(\mathrm{Ca}^{2+} \mathrm{di}-\alpha \cdot \mathrm{Ca}^{2+}{ }^{\mathrm{pwi}}\right)-\mathrm{Qf}_{\mathrm{ECW}} \cdot\left(\mathrm{Ca}^{2+} \mathrm{pwi}^{+} \mathrm{D}_{\mathrm{Ca}} / \mathrm{Qpwi} \cdot\left(\mathrm{Ca}^{2+} \mathrm{di}-\alpha \cdot \mathrm{Ca}^{2+} \mathrm{pwi}^{2}\right.\right.
$$

Legend: $\mathrm{V}_{\mathrm{Ca}}$, Ca distribution volume (1); $\mathrm{D}_{\mathrm{ca}}$, "effective" Ca dialysance (L/min); $\mathrm{Ca}^{2+} \mathrm{di}$, inlet dialysate ionized $\mathrm{Ca}$ concentration (mmol/L); $\alpha$, Donnan's factor; $\mathrm{Ca}^{2+}$ pwi, inlet plasma water ionized Ca concentration (mmol/L); $\mathrm{Qf}_{\mathrm{ECW}}$, ultrafiltrate removed from extracellular volume (L/min).

Equation 3: End-dialysis ionized plasma water calcium concentration predicted by the kinetic model $\left(\mathrm{Ca}^{2+} \mathrm{pwtP}\right)$

$$
\mathrm{Ca}^{2+} \mathrm{pwtP}=\frac{1}{\alpha} \cdot\left(\mathrm{Ca}^{2+} \mathrm{di}-\left(\mathrm{Ca}^{2+} \mathrm{di}-\alpha \cdot \mathrm{Ca}^{2+} \mathrm{pw} 0\right) \cdot\left(\frac{\mathrm{V}_{\mathrm{Ca}}}{\mathrm{V}_{\mathrm{Ca}} \mathrm{O}}\right)\left(\mathrm{D}_{\left.\mathrm{Ca} \cdot \alpha \cdot\left(\frac{1}{\mathrm{Q}_{\mathrm{ECW}}}-\frac{1}{\mathrm{ppw}}\right)\right)}\right)\right.
$$

Legend: 0 and $\mathrm{t}$ stand for initial and final values; Qpwi, plasma inlet water flow rate (1/min) Equation 4-7: Global $\left(\mathrm{gCa}^{2+} \mathrm{MB}\right)$, diffusive $\left(\mathrm{dCa}^{2+} \mathrm{MB}\right)$ convective $\left(\mathrm{cCa}^{2+} \mathrm{MB}\right)$ calcium mass balances and $\mathrm{Ca}^{2+}$ sequestration $\left(\mathrm{MCa}^{2+}\right)$ outside the extracellular fluid.

$$
\begin{aligned}
& \mathrm{MCa}^{2+}(\mathrm{mmol})=\mathrm{V}_{\mathrm{Ca}} \cdot\left(\mathrm{Ca}^{2+} \mathrm{pwtP}-\mathrm{Ca}^{2+} \mathrm{pwtM}\right)
\end{aligned}
$$

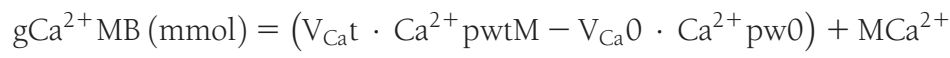

$$
\begin{aligned}
& \mathrm{dCa}^{2+} \mathrm{MB}(\mathrm{mmol})=\mathrm{V}_{\mathrm{Ca}} \mathrm{O} \cdot\left(\mathrm{Ca}^{2+} \mathrm{pwtM}-\mathrm{Ca}^{2+} \mathrm{pw}\right)+\mathrm{MCa}^{2+} \\
& \mathrm{cCa}^{2+} \mathrm{MB}(\mathrm{mmol})=\mathrm{gCa}^{2+} \mathrm{MB}-\mathrm{dCa}^{2+} \mathrm{MB}
\end{aligned}
$$

Legend: plasma water calcium concentration predicted by the kinetic model $\left(\mathrm{Ca}^{2+} \mathrm{pwtP}\right)$ and measured value normalized to pH $7.40\left(\mathrm{Ca}^{2+}\right.$ pwtM); calcium sequestration $\left(\mathrm{MCa}^{2+}\right)$; global $\left(\mathrm{gCa}^{2+} \mathrm{MB}\right)$, diffusive $\left(\mathrm{dCa}^{2+} \mathrm{MB}\right)$ convective $\left(\mathrm{cCa}^{2+} \mathrm{MB}\right)$ calcium mass balances and; $\mathrm{V}_{\mathrm{Ca}}$ calcium distribution volume. 